\title{
Relation between augmentation index and adiponectin during one-year metformin treatment for nonalcoholic steatohepatosis: effects beyond glucose lowering?
}

\author{
Marina Shargorodsky ${ }^{1,5^{*}}$, Elena Omelchenko ${ }^{2,5}$, Zipora Matas ${ }^{3,5}$, Mona Boaz ${ }^{4,5}$ and Dov Gavish ${ }^{2,5}$
}

\begin{abstract}
Background: Insulin resistance (IR) is the major driving force behind development and progression of atherosclerosis in patients with nonalcoholic fatty liver disease (NAFLD). Therefore, correction of IR is a relevant therapeutic target. We performed the current trial to evaluate whether 12- month metformin therapy improves vascular stiffness in patients with NAFLD and to assess if this improvement is associated with change in glucose control, insulin resistance or circulating adiponectin.

Methods: In randomized, placebo controlled study, 63 patients with NAFLD were assigned to one of two groups: Group 1 received daily metformin; Group 2 received placebo. Central aortic augmentation index (Al) was performed using SphygmoCor (version 7.1, AtCor Medical, Sydney, Australia) at baseline, at 4-and 12-month treatment period. Metabolic parameters, insulin resistance markers and serum adiponectin levels were determined.

Results: In placebo group: Al did not improve during the treatment period. Liver function and adiponectin levels did not change during the study.

In multiple linear regression analysis, the independent predictors of arterial stiffness improvement were metformin treatment and increase in circulating adiponectin levels.

Among metformin treated patients: Al decreased significantly during the study. ALP and ALT decreased during initial 4month treatment period, however raised to the pretreatment levels after 12 months. Serum adiponectin level tended to increase during treatment period with metformin.
\end{abstract}

Conclusions: Metformin treatment was associated with significant decrease in Al during one year treatment in NAFLD patients. These beneficial vascular effects was associated with exposure to metformin per se as well as change in adiponectin levels suggesting that metformin may mediate its vascular effects via glicemic control-independent mechanisms.

Trial registry: no: NCT01084486

\section{Background}

Insulin resistance is one of the major driving forces behind development and progression of atherosclerosis in patients with nonalcoholic fatty liver disease (NAFLD) [1-4]. Metformin is a potent insulin sensitizer, and, as such, has the potential to alleviate the cardiovascular

\footnotetext{
*Correspondence: marinas@wolfson.health.gov.il

'Department of Endocrinology, Wolfson Med Center, POB 5, Holon 58100, Israel

${ }^{5}$ Sackler School of Medicine, Tel Aviv University, Tel Aviv, Israel

Full list of author information is available at the end of the article
}

damage caused by insulin resistance. Several clinical studies have shown significant improvement in insulin resistance and liver function as well as positive histological changes in patients treated with metformin $[5,6]$. We have previously reported that 4 months metformin treatment was associated with a significant improvement in arterial stiffness in patients with nonalcoholic fatty liver disease [7]. Metformin has beneficial effects on glucose control as well as traditional cardiovascular risk factors and is associated with decreased cardiovascular 
morbidity and mortality in diabetic patients [8]. However accumulating evidence suggests that metformin may affect the risk of atherothrombotic disease through mechanisms other than lowering glycemia, possibly by vasculoprotective effects [9-11]. Recently published data indicate that metformin treatment is associated with a significant increase in serum adiponectin [12], which plays an important role in insulin sensitivity, inflammation, lipid metabolism and atherogenesis [13-15].

Since the long-term vascular impact of treatment, which improves insulin sensitivity in patients with NAFLD, has not been investigated, the present study was designed to determine the long-term vascular effect of metformin treatment in this population. Central aortic augmentation index, determined invasively, has been reported to be a strong, independent risk marker for premature coronary artery disease [16]. Although AI is influenced by several parameters, such as age, heart rate, SVR, left ventricular hypertrophy, endothelial function, this parameter is considered to be reliable and valid measure of arterial stiffness, and significantly and independently associated with target organ damage [17] as well as cardiovascular morbidity and mortality [18,19]. Measurement of arterial stiffness may serve not only as cardiovascular risk assessment [20] but also as an indicator of treatment benefit [21].

Two questions were addressed: (1) Whether 12month metformin therapy improves vascular stiffness in patients with NAFLD. (2) Whether effect of long-term metformin treatment on arterial stiffness is dependent of glycaemic control, insulin resistance and/or circulating adiponectin levels.

\section{Methods}

\section{Subjects}

As previously reported, 63 patients (32 males and 31 females) diagnosed with nonalcoholic fatty liver disease were recruited from the outpatient clinic at the Wolfson Medical Center to participate in the study [7]. The study was a randomized, placebo controlled. The diagnosis of NAFLD was based on the results of abdominal ultrasonography and exclusion of viral, autoimmune or drug induced liver disease as well as alcohol intake of more that $20 \mathrm{~g} /$ day. Fatty liver disease was diagnosed on the basis on four sonographic criteria: (1) a diffuse hyperechoic echotexture (bright liver), (2) increased echotexture compared with the kidneys, (3) vascular blurring, and (4) deep attenuation [22].

Screening procedures included physical examination, complete blood chemistry, complete blood count, urinalysis and electrocardiography.

Patients with a history of unstable angina, myocardial infarction, cerebrovascular accident or major surgery within the 6 months preceding the study were excluded.
Patients with unbalanced endocrine disease or any disease that might affect absorption of medications were excluded, as were patients with plasma creatinine $>1.5 \mathrm{mg} / \mathrm{dl}$, elevation of liver enzymes to more that twice the upper normal limit or electrolyte abnormalities (plasma potassium levels $>5.5 \mathrm{mg} / \mathrm{dl}$ ). Patients included in the study were stabilised on optimal medical treatment in the outpatient clinic for up to 3 months, and an effort was made not to change treatment during the study. Patients unbalanced during the 3 month run-in period were not included in the study. All concomitant medications were kept stable to prevent possible effects on the study variables. The patients were instructed to consult the study physician if any change in medical treatment was suggested by another physician. None of the study participants had previously received metformin therapy.

Patients were randomly assigned to one of two groups: Group 1 received oral daily metformin at a dose of 850 $1700 \mathrm{mg} /$ day; Group 2 received matching placebo capsules. Of the 63 patients recruited to the study, 52 completed the 4-month treatment period (27 from Group1 and 25 from Group 2). And 41 completed the 12-month treatment period (19 from Group 1 and 22 from Group 2). Metformin therapy was generally well tolerated; only one patient from metformin group withdrew because of gastrointestinal side effects during initial 4 month and 1 patient during additional 8 months. Additionally, 1 patient from metformin group did not return for follow-up because prolonged hospitalization for respiratory infection. In control group 2 patient discontinued follow-up because hospitalization due to urinary tract infection and elective hospitalization for cholecystectomy. The other participants who dropped out from the study were classed as 'lost to follow-up'.

\section{Informed consent}

The study was approved by the Institutional Review Board and the patients signed a full informed consent before participation. The study had been registered in ClinicalTrials.gov registry. The registration number: NCT01084486.

\section{Biochemical parameters}

Blood sampling for full chemistry and metabolic parameters, including fasting glucose, fasting insulin, lipid profile, hs-CRP, liver function tests and plasma adiponectin was performed at baseline, after 4-month treatment period and at the end of the study. Glucose was measured using the Aeroset chemistry system (Abbott Diagnostics), high-density lipoprotein cholesterol (HDL), and triglycerides were assayed using an Aeroset automated analyzer (Abbott Diagnostics, Berkshire, UK), low-density lipoprotein cholesterol (LDL) was calculated 
using Friedewald's formula and insulin was measured using an immunometric assay specific for human insulin (Invitron, Monmouth, UK). Adiponectin was determined by a commercial sandwitch enzyme immunoassay technique, R\&D Systems, Minneapolis, USA (catalog number DRP300) with $2.8 \%$ intra-assay and $6.5 \%$ inter-assay variability.

Homeostasis model assessment-insulin resistance (HOMA-IR) was calculated by the following formula: fasting plasma insulin $(\mathrm{mU} / \mathrm{ml}) \mathrm{x}$ fasting plasma glucose $(\mathrm{mg} / \mathrm{dl}) / 405$.

\section{Blood pressure and pulse wave velocity measurement}

Blood pressure (BP) was measured using an automated digital oscillometric device (Omron model HEM 705-CP, Omron Corporation, Tokyo, Japan) and a mean of three readings was taken. The radial pressure waveform was recorded and subsequently transformed by using a validated generalized transfer function incorporated in the SphygmoCor (version 7.1, AtCor Medical, Sydney, Australia) to give an estimate of the corresponding central ascending aortic pulse wave. With the integral software, the central augmented pressure was calculated as the difference between the early and late systolic peaks of the estimated central pressure waveform. Central aortic augmentation index (AI) was calculated as the augmented pressure expressed as a percentage of the pulse pressure.

Arterial stiffness was determined at baseline visit at the end of 4-month and 12-month treatment period.

\section{Statistical analysis}

Analysis of data was carried out using SPSS 10.0 statistical analysis software (SPSS Inc., Chicago, IL, USA). For continuous variables, such as hemodynamic, biochemistry and arterial elasticity parameters, descriptive statistics were calculated and reported as mean \pm standard deviation. Normalcy of distribution of continuous variables was assessed using the Kolmogorov-Smirnov test (cut off at $p=0.01$ ). Categorical variables such as sex and co-morbidities were described using frequency distributions and are presented as frequency (\%). Continuous variables were compared by treatment group using the $t$ test for independent samples. Additionally, univariate general linear modeling (GLM) was used to compare outcomes by treatment assignment controlling for baseline values of covariates. Within a given treatment group, the $t$-test for paired samples was used to compare before vs. post-treatment values of outcomes. Categorical variables were compared between groups using the chi-square test. All tests are two-sided and considered significant at $p<0.05$.

\section{Results}

The clinical characteristics of the study groups are presented in Table 1. As can be seen, there were no significant differences between the two groups in terms of age, sex, presence of cardiovascular risk factors, baseline blood pressure level, baseline blood pressure level, liver function and arterial stiffness. Concomitant medications were distributed similarly in both groups at the start and end of the study. The two variables, fasting glucose and serum adiponectin levels, differed significantly by groups at baseline. There were no notable differences in the participant characteristics at entry into the study between those who attended the final data-collection visit and the individuals who did not.

\section{Changes in hemodynamic, arterial stiffness and metabolic parameters in metformin treated patients}

As can be seen in Table 2, both groups were similar at baseline in terms of hemodynamic and arterial stiffness parameters. Systolic (SBP) as well as diastolic blood pressure (DBP) were similar in both groups at baseline as well at the end of the study. AI decreased significantly during the treatment period: from $31.4+/-10.2$ to 23.1 $+/-8.5 \%$ after 4 month $(p<0.0001)$ and $24.8 \pm 7.9 \%$ after 12 month treatment period $(p=0.009)$.

As shown in Table 2, significant declines in fasting glucose, triglycerides and alkaline phosphatase (ALP) together with a significant increase in HDL cholesterol were observed during the initial 4 months in metformin treated patients. CRP and ALT decreased marginally during 4-month treatment period. However, after 4 months, there was no further improvement in fasting glucose and HDL cholesterol and there was gradual rise in ALP and ALT to the pretreatment levels. Insulin resistance assessed by HOMA-IR decreased significantly during 12 month treatment period. Serum adiponectin level tended to increase during treatment period with metformin; however, this increase did not reach statistical significance.

\section{Changes in hemodynamic, arterial stiffness and metabolic parameters in placebo group}

As shown in Table 3, AI did not change significantly during the initial 4 month treatment period. Moreover, AI increased marginally after 12 months of the study $(p=0.089)$. No change was detected in either SBP or DBP during 12 month follow-up period. ALT, AST and serum adiponectin levels did not change in placebo group during the study.

\section{Between group comparisons}

As can be seen in Figure 1, AI did not differ significantly between the groups at baseline. However, AI was significantly lower in patients treated with metformin than in 
Table 1 Demographic and clinical characteristics of study patients

\begin{tabular}{|c|c|c|c|}
\hline Variables & $\begin{array}{c}\text { Patients } \\
\text { received } \\
\text { metformin } \\
(n=32)\end{array}$ & $\begin{array}{c}\text { Placebo } \\
\text { group } \\
(n=31)\end{array}$ & p-value \\
\hline Male/Female & $17 / 15$ & $14 / 17$ & 0.352 \\
\hline Age (y) & $51.9 \pm 10.9$ & $55.2 \pm 14.0$ & 0.306 \\
\hline BMI $\left(\mathrm{kg} / \mathrm{m}^{2}\right)$ & $32.6 \pm 5.8$ & $31.5 \pm 5.6$ & 0.410 \\
\hline Current smokers, n (\%) & $4(12.5 \%)$ & $2(6.5 \%)$ & 0.391 \\
\hline Hypertension, n (\%) & $15(46.9 \%)$ & $15(48.4 \%)$ & 0.599 \\
\hline Dyslipidemia, n (\%) & $21(65.6 \%)$ & $14(45.2 \%)$ & 0.079 \\
\hline DM/IFG, n (\%) & \multicolumn{2}{|c|}{$6 / 14(18.8 / 43.8 \%) 2 / 13$ (6.5/41.9\%) } & 0.128 \\
\hline \multicolumn{4}{|l|}{ Concomitant medication: } \\
\hline Antidiabetic treatment (\%) & $6(18.8 \%)$ & $2(6.5 \%)$ & 0.194 \\
\hline Statins (\%) & $18(56.3 \%)$ & $11(35.5 \%)$ & 0.079 \\
\hline ACEIs/ARBs (\%) & $9(28.1 \%)$ & $9(29.0 \%)$ & 0.609 \\
\hline Diuretics (\%) & $1(3.1 \%)$ & $6(19.4 \%)$ & 0.104 \\
\hline B-blockers (\%) & $9(28.1 \%)$ & $10(32.3 \%)$ & 0.784 \\
\hline CCB-blockers (\%) & $5(15.6 \%)$ & $8(25.8 \%)$ & 0.351 \\
\hline Aspirin (\%) & $13(40.6 \%)$ & $9(29.0 \%)$ & 0.292 \\
\hline Baseline systolic BP (mm/Hg) & $138.8 \pm 17.6$ & $133.6 \pm 18.1$ & 0.258 \\
\hline Baseline diastolic BP (mm/Hg) & $80.1 \pm 9.8$ & $74.6 \pm 13.5$ & 0.072 \\
\hline Baseline heart rate (bts/min) & $68.6 \pm 12.3$ & $62.9 \pm 8.4$ & 0.034 \\
\hline Baseline fasting glucose (mg/dl) & $131.8 \pm 51.3$ & $98.3 \pm 14.8$ & 0.001 \\
\hline Baseline total cholesterol (mg/dl) & $184.5 \pm 43.3$ & $191.1 \pm 37.0$ & 0.523 \\
\hline Baseline LDL Cholesterol (mg/dl) & $110.4 \pm 37.9$ & $112.7 \pm 34.2$ & 0.811 \\
\hline Baseline HDL-cholesterol (mg/dl) & $42.6 \pm 13.0$ & $48.2 \pm 15.2$ & 0.123 \\
\hline Baseline triglycerides (mg/dl) & $185.5 \pm 112.0$ & $143.1 \pm 63.2$ & 0.070 \\
\hline Baseline hs-CRP (mg/dl) & $0.9 \pm 1.1$ & $0.9 \pm 1.4$ & 0.969 \\
\hline Baseline AST (U/I) & $28.9 \pm 16.8$ & $28.0 \pm 8.2$ & 0.796 \\
\hline Baseline ALT (U/I) & $38.0 \pm 29.9$ & $32.6 \pm 15.3$ & 0.377 \\
\hline Baseline ALP (U/I) & $67.7 \pm 17.0$ & $72.2 \pm 23.5$ & 0.386 \\
\hline Baseline creatinine (mg/dl) & $0.9 \pm 0.1$ & $0.9 \pm 0.2$ & 0.723 \\
\hline Baseline urea (mg/dl) & $32.0 \pm 10.0$ & $32.0 \pm 9.0$ & 1.000 \\
\hline Baseline adiponectine (ng/ml) & $6130.5 \pm 2872.6$ & $9156.3 \pm 6365.2$ & 0.020 \\
\hline Baseline Al (\%) & $31.4 \pm 11.1$ & $30.0 \pm 10.7$ & 0.628 \\
\hline
\end{tabular}

the placebo group after initial 4 months $(p=0.038)$ as well as at the end of the study $(p=0.021)$. During one year follow up AI decreased by $7.47 \%$ in the active treatment group and increases by $4.45 \%$ in the control group $(p=0.004)$. Because fasting glucose and serum adiponectin levels differed significantly by groups at baseline, univariate GLM analysis was carried out to control for these findings. Baseline mean arterial pressure (MAP), as representative of hemodynamic values was also included as a covariate in this model. Significant by-
Table 2 Changes in hemodynamic, arterial stiffness and metabolic parameters in metformin treated patients during 12 months follow up

\begin{tabular}{|c|c|c|c|c|c|}
\hline \multirow[t]{2}{*}{ Variable } & \multicolumn{5}{|c|}{ Metformin treated patients } \\
\hline & Baseline & 4 month & $\begin{array}{l}\text { p-value } \\
\text { V1 vs V2 }\end{array}$ & $2^{12 \text { month }}$ & $\begin{array}{l}\text { p-value } \\
\text { V1 vs V3 }\end{array}$ \\
\hline $\begin{array}{l}\text { Systolic } \quad B F \\
(\mathrm{~mm} / \mathrm{Hg})\end{array}$ & BP139.0 \pm 17.9 & $137.2 \pm 20.1$ & 0.565 & $131.5 \pm 14.0$ & 0.060 \\
\hline $\begin{array}{l}\text { Diastolic } \\
(\mathrm{mm} / \mathrm{Hg})\end{array}$ & BP80.6 \pm 9.2 & $78.4 \pm 9.0$ & 0.403 & $80.9 \pm 8.8$ & 0.921 \\
\hline $\begin{array}{l}\text { Aortic } \\
(\mathrm{mm} / \mathrm{Hg})\end{array}$ & AP15.6 \pm 9.1 & $11.4 \pm 7.6$ & 0.001 & $12.8 \pm 5.2$ & 0.257 \\
\hline $\mathrm{Al}(\%)$ & $31.4 \pm 10.2$ & $23.1 \pm 8.5$ & $<0.0001$ & $24.8 \pm 7.9$ & 0.009 \\
\hline $\begin{array}{l}\text { Total } \\
\text { Cholesterol } \\
(\mathrm{mg} / \mathrm{dl})\end{array}$ & $179.3 \pm 40.3$ & $176.7 \pm 32.2$ & 0.722 & $178.2 \pm 25$ & 0.985 \\
\hline $\begin{array}{l}\text { Triglycerides } \\
\text { (mg/dl) }\end{array}$ & is $195.4 \pm 119.1$ & $157.9 \pm 97.4$ & 0.033 & $195.7 \pm 149.7$ & 0.574 \\
\hline $\begin{array}{l}\text { HDL- } \\
\text { cholesterol } \\
\text { (mg/dl) }\end{array}$ & $41.3 \pm 12.2$ & $45.7 \pm 15.0$ & 0.001 & $42.2 \pm 11.6$ & 0.768 \\
\hline $\begin{array}{l}\text { LDL } \\
\text { Cholesterol } \\
\text { (mg/dl) }\end{array}$ & $103.5 \pm 37.3$ & $103.7 \pm 22.1$ & 0.979 & $111.8 \pm 23.8$ & 0.286 \\
\hline ALP $(U / I)$ & $66.5 \pm 17.8$ & $61.1 \pm 15.6$ & 0.007 & $65.2 \pm 19.7$ & 0.452 \\
\hline $\operatorname{ALT}(\mathrm{U} / \mathrm{l})$ & $38.5 \pm 31.7$ & $29.3 \pm 16.2$ & 0.092 & $39.2 \pm 21.8$ & 0.838 \\
\hline AST (U/I) & $29.0 \pm 18.0$ & $25.4 \pm 9.7$ & 0.300 & $30.6 \pm 11.6$ & 0.991 \\
\hline $\begin{array}{l}\text { hs-CRP } \\
\text { (mg/dl) }\end{array}$ & $1.0 \pm 1.1$ & $0.5 \pm 0.4$ & 0.081 & $0.7 \pm 0.9$ & 0.448 \\
\hline $\begin{array}{l}\text { Fasting } \\
\text { glucose } \\
\text { (mg/dl) }\end{array}$ & $135.0 \pm 52.8$ & $115.8 \pm 27.0$ & 0.036 & $125.7 \pm 54$ & 0.185 \\
\hline $\begin{array}{l}\text { Adiponectin } \\
(\mathrm{ng} / \mathrm{ml})\end{array}$ & $5661.8 \pm 2820$ & $06166.6 \pm 326$ & 50.171 & $6102.4 \pm 2139$ & 90.746 \\
\hline HOMA-IR & $7.2 \pm 6.3$ & $7.3 \pm 10.9$ & 0.920 & $5.7 \pm 6$ & 0.042 \\
\hline
\end{tabular}

group differences in $\Delta \mathrm{AI}$ (change from baseline AI) persisted even after adjustment for baseline values of MAP, fasting glucose and serum adiponectin levels $(p=0.004)$.

\section{General linear model}

In this repeated measures model, the pattern of change in fasting glucose and adiponectin over time was significantly different between metformin treated patients and controls $(p=0.004$ and $p=0.001$, respectively). The pattern of change in HOMA-IR over time did not differ by treatment group.

To determine whether the change in arterial stiffness result from improved glycemic control per se in active treatment group or from other factors such as exposure to metformin, change in insulin resistance or adiponectin levels, general linear model of change from baseline AI $(\Delta \mathrm{AI})$ was carried out. In this model change from 
Table 3 Changes in hemodynamic, arterial stiffness and metabolic parameters in control group during 12 months follow up

\begin{tabular}{llllll}
\hline Variable & \multicolumn{5}{c}{ Placebo group } \\
\cline { 2 - 5 } & Baseline & 4 month & p-value V1 vs V2 & 12 month & p-value V1 vs V3 \\
\hline Systolic BP (mm/Hg) & $133.0 \pm 19.5$ & $139.8 \pm 19.3$ & 0.091 & $125.4 \pm 25.5$ & 0.477 \\
Diastolic BP (mm/Hg) & $73.3 \pm 14.1$ & $75.0 \pm 9.4$ & 0.589 & $73.5 \pm 11.9$ & 0.842 \\
Aortic AP (mm/Hg) & $15.6 \pm 9.3$ & $20.2 \pm 18.6$ & 0.271 & $17.2 \pm 12$ & 0.587 \\
Al (\%) & $29.9 \pm 11.0$ & $29.0 \pm 11.5$ & 0.625 & $34.6 \pm 12.1$ & 0.089 \\
Total Cholesterol (mg/dl) & $190.0 \pm 38.5$ & $186.2 \pm 32.6$ & 0.616 & $175.8 \pm 30.6$ & 0.024 \\
Triglycerides (mg/dl) & $140.8 \pm 58.0$ & $135.0 \pm 57.6$ & 0.588 & $146.2 \pm 70.5$ & 0.447 \\
HDL-cholesterol (mg/dl) & $47.8 \pm 14.3$ & $49.6 \pm 15.3$ & 0.329 & $49 \pm 15.9$ & 0.278 \\
LDL Cholesterol (mg/dl) & $110.8 \pm 35.2$ & $109.0 \pm 25.7$ & 0.786 & $103.3 \pm 27.2$ & 0.521 \\
ALP (U/l) & $74.3 \pm 24.6$ & $67.4 \pm 19.6$ & 0.065 & $71.5 \pm 22.9$ & 0.659 \\
ALT (U/l) & $34.9 \pm 15.8$ & $29.7 \pm 16.3$ & 0.120 & $32.1 \pm 20.6$ & 0.315 \\
AST (U/l) & $29.4 \pm 8.4$ & $27.4 \pm 8.3$ & 0.246 & $29.3 \pm 12.9$ & 0.957 \\
hs-CRP (mg/dl) & $1.0 \pm 1.5$ & $0.5 \pm 0.5$ & 0.139 & $0.5 \pm 0.7$ & 0.156 \\
Fasting glucose (mg/dl) & $98.1 \pm 15.9$ & $103.9 \pm 18.5$ & 0.015 & $98 \pm 14.2$ & 0.651 \\
Adiponectin (ng/ml) & $10251.8 \pm 6610$ & $10020.2 \pm 5648$ & 0.699 & $10255.8 \pm 5704.4$ & 0.529 \\
HOMA-IR & $5.4 \pm 4.9$ & $4.9 \pm 7.5$ & 0.682 & $4.97 \pm 8$ & 0.721 \\
\hline
\end{tabular}

baseline glucose, adiponectin levels, HOMA-IR as well as age, sex, baseline mean arterial pressure, baseline AI were included. Additionally, metformin exposure was included as a fixed factor. The model was significant $(p=0.006)$ and explained $47.5 \%$ of the variability in this outcome. Significantly associated with $\Delta$ AI were baseline AI $(p=0.001)$, exposure to metformin $(p=0.037)$ and change from baseline adiponectin levels $(p=0.032)$. Change from baseline glucose was not associated with the outcome $(p=0.709)$ (Table 4$)$.

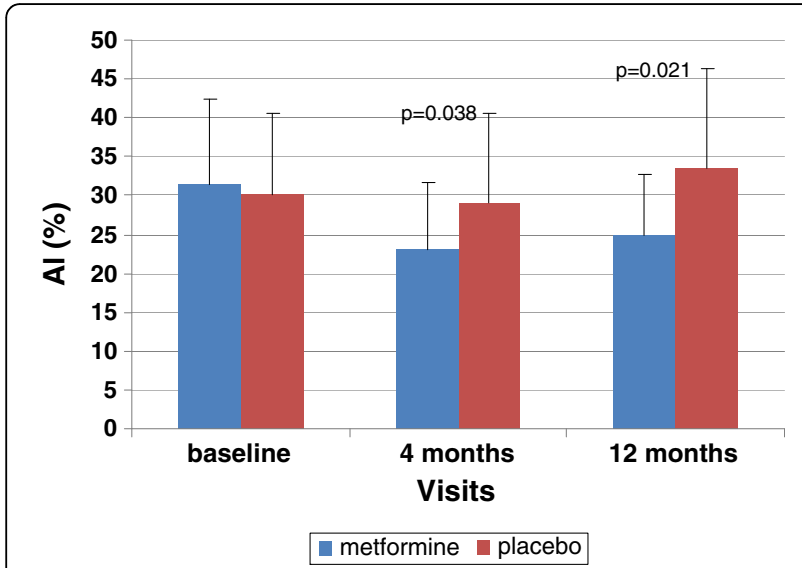

Figure 1 Augmentation Index by groups during 12-month follow-up. ${ }^{*} p$-value $<0.05$, ${ }^{* *} p$-value $<0.01,{ }^{* * *} p$-value $<0.001$. Values are means \pm SD.

\section{Discussion}

The present randomized, placebo controlled study demonstrates that one year metformin treatment was associated with a significant improvement in arterial stiffness in patients with nonalcoholic fatty liver disease. This beneficial vascular effect was associated with exposure to metformin per se as well as changes in circulating adiponectin levels.

Previous clinical and experimental data show the beneficial vascular effect of metformin. Metformin treatment increases insulin action in peripheral tissue, resulting improvement in endothelium-dependent vasodilatation [23], decrease in the local activity of growth factors in vascular tissue, which in turn decrease a development of vascular smooth muscle cell hypertrophy $[9,11,24]$. It has been shown that metformin has beneficial effect on

Table 4 General liner model of Al

\begin{tabular}{lcccc}
\hline Source & Type III Sum of Squares & Mean Square & $\mathbf{F}$ & Sig. \\
\hline Corrected Model & $1953.803(\mathrm{a})$ & 195.380 & 3.899 & 0.004 \\
Age & 151.237 & 151.237 & 3.018 & 0.096 \\
Sex & 51.227 & 51.227 & 1.022 & 0.323 \\
$\Delta$ Fast. Glucose & 7.181 & 7.181 & 0.143 & 0.709 \\
$\Delta$ HBA1C & 7.083 & 7.083 & 0.141 & 0.711 \\
$\Delta$ HOMA-IR & 49.744 & 49.744 & 0.993 & 0.330 \\
$\Delta$ Adiponectin & 263.214 & 263.214 & 5.253 & 0.032 \\
$\Delta$ MAP & 10.152 & 10.152 & 0.203 & 0.657 \\
Group & 247.677 & 247.677 & 4.943 & 0.037 \\
\hline
\end{tabular}


nitroxidation, endothelial function and IMT in patients with metabolic syndrome [25] and significantly improves arterial stiffness and endothelial function in young women with polycystic ovary syndrome [26]. In addition, previously published data indicate that metformin treatment decreases matrix metalloproteinase (MMP)-9 in drug naive diabetic patients [27] and improves endothelial function in patient with type 2 diabetes as well as first-degree relatives of type 2 diabetic patients $[9,28]$. We have previously reported that 4 months metformin treatment was associated with a significant improvement in arterial stiffness in patients with nonalcoholic fatty liver disease [7]. This beneficial vascular effect was accompanied by an improvement in glucose and lipid metabolism as well as liver enzymes such as ALP and ALT. Although the anti-atherogenic effect of short term metformin has been assessed previously, data regarding the long-term impact of metformin on arterial stiffness are limited. In the present study, investigating vascular effect of metformin treatment during one year, we observed impressive improvement in arterial stiffness in patient with NAFLD treated with metformin. Moreover, marginal increase in AI has been observed in the placebo group during 12 month follow up. These vascular changes can be conceptualized as the "natural" development expected in untreated individuals with NAFLD. This means that we would have expected an increase in arterial stiffness over time in subjects with hepatic steatosis, but treatment by a potent insulin sensitizer not only prevented the "natural" increase, it reversed the anticipated process and produced an improvement in arterial stiffness during a relatively short (4 months) as well as long-term (one year) period of time.

Another important observation in our study is the long term effect of metformin treatment on liver function in patients with NAFLD, since data regarding the impact of metformin on hepatic steatosis are limited and controversial. Metformin have been shown to activate AMP-activated protein kinase (AMPK) in hepatocytes as well as phosphorylation of acetyl-CoA carboxylase, resulting in decreasing hepatic lipogenesis [23]. It has been demonstrated that the liver protective mechanisms of metformin in non-alcoholic fatty liver disease may be contributed to down-regulation of secretory phospholipase A2 mRNA expression, decrease in serum secretory phospholipase A2, lysophosphatidylcholine and lower inflammatory response in rat model [29] Although animal data in experimental models have demonstrated that this treatment is able to retard the progression of hepatosteatosis, results from human studies have been varied. Studies in pediatric subjects with NAFLD show that metformin wasn't superior to placebo in attaining the primary outcome of sustained reduction in ALT level [30]. On the other hand, previously published data from the Diabetes Prevention Program, have demonstrated that serum ALT activity as a marker for NAFLD was consistently lower in those treated with metformin compared with placebo during 3 year follow-up. However, this effect of metformin therapy on ALT was mediated by weight loss [31]. Additionally, the effect of metformin was tested in subjects with NASH consuming metformin or lipid and calorie-restricted diet for 6 months. Liver enzyme activities as well as insulin sensitivity improved in the metformin-treated patients, while no significant differences in necroinflammatory activity and fibrosis were found between the groups [32]. In the present study a significant decrease in alkaline phosphatase and marginal decrease in ALT were observed during the initial 4 months in metformin treated patients. However, after 12 months of treatment, a gradual rise in ALP and ALT to the pretreatment levels was observed.

The present study demonstrated that beneficial effect of long-term metformin treatment on arterial stiffness was associated with change in circulating adiponectin, a collagen-like protein specifically expressed in human adipose cells which plays an important role in insulin sensitivity, inflammation and atherogenesis [33,34]. Recently adiponectin has been considered as a possible link between liver dysfunction and atherosclerotic vascular disease in patients with NAFLD [35]. In the present study, we did not observe significant changes in circulating adiponectin levels, however serum adiponectin level tended to increase in metformin treated patients during the study.

Moreover, the pattern of change in adiponectin over time was significantly different between metformin treated patients and controls. Additionally, in general linear model change from baseline adiponectin was significantly associated with $\Delta$ AI.

The findings of the present study suggest that circulating adiponectin level affects arterial stiffness more strongly than insulin resistance per se. Nevertheless, further studies are needed to clarify the clinical effects of the circulating adiponectin on arterial stiffness.

Our study has several limitations. Our study has focused on patients with nonalcoholic fatty liver disease, therefore, the application of our findings to other patient populations remains uncertain. Since the present study includes a small number of participants and a relatively large number of dropouts, additional studies are required to establish the beneficial vascular effect of metformin as well as its clinical impact on cardiovascular outcomes in subjects with nonalcoholic fatty liver disease. Moreover, because serum levels of total adiponectin were assayed in the present study, the impact of different multimers of adiponectin (low, middle and high molecular weight form) on vascular pathophysiology remains unclear. 


\section{Conclusions}

We have demonstrated that one year metformin treatment improves augmentation index in patients with nonalcoholic fatty liver disease. These beneficial vascular effects was associated with exposure to metformin per se as well as change in circulating adiponectin levels, suggesting that metformin may mediate its vascular effects via glicemic control-independent mechanisms.

\section{Competing interests}

The corresponding author and all of the authors have no conflicts of interest or financial or other contractual agreements that might cause conflicts of interest.

\section{Authors' contributions}

MS and DG contributed to the study conception and design. EO was responsible for the data acquisition. MB performed the analysis and interpretation of data. ZM carried out the immunoassays. MS was responsible for review the existing literature and for writing the first draft of the paper. All authors performed a critical revision of the manuscript for important intellectual content. All authors read and approved the final manuscript.

\section{Funding}

This research did not receive any specific grant from any funding agency in the public, commercial or not-for-profit sector

\section{Author details}

'Department of Endocrinology, Wolfson Med Center, POB 5, Holon 58100, Israel. '2Department of Medicine, Wolfson Med Center, POB 5, Holon 58100, Israel. ${ }^{3}$ Department of Biochemistry, Wolfson Med Center, POB 5, Holon 58100, Israel. ${ }^{4}$ Epidemiology and Research Unit, Wolfson Med Center, POB 5, Holon 58100, Israel. ${ }^{5}$ Sackler School of Medicine, Tel Aviv University, Tel Aviv, Israel.

Received: 15 November 2011 Accepted: 12 March 2012

Published: 7 June 2012

\section{References}

1. Bugianesi E, Gastaldelli A, Vanni E, Gambino R, Cassader M, Baldi S, Ponti V, Pagano G, Ferrannini E, Rizzetto M: Insulin resistance in non-diabetic patients with non-alcoholic fatty liver disease: sites and mechanisms. Diabetologia 2005, 48:634-642.

2. Targher G, Bertolini L, Padovani R, Zenari L, Zoppini G, Falezza G: Relation of nonalcoholic hepatic steatosis to early carotid atherosclerosis in healthy men: role of visceral fat accumulation. Diabetes Care 2004 7:1498-1500.

3. Brea A, Mosquera D, Martin E, Arizti A, Cordero JL, Ros E: Nonalcoholic fatty liver disease is associated with carotid atherosclerosis: a case-control study. Arterioscler Thromb Vasc Biol 2005, 25:1045-1500.

4. Targher G, Bertolini L, Padovani R, Rodella S, Zoppini G, Zenari L, Cigolini M, Falezza G, Arcaro G: Relations between Carotid Artery Wall Thickness and Liver Histology in Subjects with Nonalcoholic Fatty Liver Disease. Diabetes Care 2006, 29:1325-1330.

5. Blaszik H, Ferrentino N, Forsell S, Stander D, Lidofsky S: A pilot study of metformin as treatment for nonalcoholic steatohepatosis. Gastroenterology 2005, 122:M1699.

6. Marchesini G, Brizi M, Bianchi G, Tomassetti S, Zoli M, Melchionda N: Metformin in non-alcoholic steatohepatitis. Lancet 2001, 358:893-894.

7. Sofer E, Boaz M, Matas Z, Mashavi M, Shargorodsky M: Treatment with insulin sensitizer metformin improves arterial properties, metabolic parameters, and liver function in patients with nonalcoholic fatty liver disease: a randomized, placebo-controlled trial. Metabolism 2011, 60(9):1278-1284.

8. UK Prospective Diabetes Study (UKPDS) Group: Effect of intensive bloodglucose control with metformin on complications in overweight patients with type 2 diabetes (UKPDS 34). Lancet 1998, 352:854-865.

9. de Aguiar LG Kraemer, Bahia LR, Villela N, Laflor C, Sicuro F, Wiernsperger N, Bottino D, Bouskela E: Metformin improves endothelial vascular reactivity in first-degree relatives of type 2 diabetic patients with metabolic syndrome and normal glucose tolerance. Diabetes Care 2006, 29:1083-1089.

10. Jager J, Kooy A, Lehert PH, Bets D, Wulffele MG, Teerlink T, Scheffer PG, Schalkwijk CG, Donker AJM, Stehouwer CDA: Effect of short-term treatment with metformin on markers of endothelial function and inflammatory activity in type 2 diabetes mellitus: a randomized, placebo-controled trial. J Intern Med 2005, 257:100-109.

11. Grant PJ: Beneficial effects of metformin on haemostasis and vascular function in man. Diabet Med 2003, 29:6S44-6S52.

12. Araki T, Emoto M, Teramura M, Yokoyama H, Mori K, Hatsuda S, Maeno T, Shinohara K, Koyama H, Shoji T, Inaba M, Nishizawa Y: Effect of adiponectin on carotid arterial stiffness in type 2 diabetic patients treated with pioglitazone and metformin. Metabolism 2006, 55(8):996-1001.

13. Ouchi N, Kihara S, Arita Y, Nishida M, Matsuyama A, Okamoto Y: Adipocytederived plasma protein, adiponectin, suppresses lipid accumulation and class A scavenger receptor expression in human monocyte-derived macrophages. Circulation 2001, 103:1057-1063.

14. Tan KCB, Xu A, Chow WS, Lam MCW, Ai VHG, Tam SCF, Lam KSL: Hypoadiponectinemia is associated with impaired endotheliumdependent vasodilation. J Clin Endocrinol Metab 2004, 89:765-769.

15. Störk S, Bots ML, Angerer P, Schacky C, Grobbee DE, Angermann CE, Seufert J: Low levels of adiponectin predict worsening of arterial morphology and function. Atherosclerosis 2007, 194:e147-e153.

16. Weber T, Auer J, O'Rourke MF, Kvas E, Lassnig E, Berent R, Eber B: Arterial stiffness, wave reflections, and the risk of coronary artery disease. Circulation 2004 Jan 20, 109(2):184-189.

17. Gomez-Marcos MA, Recio-Rodríguez Jl, Patino-Alonso MC, Agudo-Conde C, Gomez-Sanchez L, Rodriguez-Sanchez E, Gomez-Sanchez M, Garcia-Ortiz L: Yearly evolution of organ damage markers in diabetes or metabolic syndrome: data from the LOD-DIABETES study. Cardiovasc Diabetol 2011, 10:9.

18. Laurent S, Boutouyrie P, Asmar R, Gautier I, Laloux B, Guize L, Ducimetiere P, Benetos A: Aortic stiffness is an independent predictor of all-cause and cardiovascular mortality in hypertensive patients. Hypertension 2001, 37:1236-1241

19. Cruickshank K, Riste L, Anderson SG, Wright JS, Dunn G, Gosling RG: Aortic pulse-wave velocity and its relationship to mortality in diabetes and glucose intolerance. An integrated index of vascular function? Circulation 2002, 106:2085-2090.

20. Shin JY, Lee HR, Lee DC: Increased arterial stiffness in healthy subjects with high-normal glucose levels and in subjects with pre-diabetes. Cardiovasc Diabetol 2011, 10:30

21. Asmar RG, London GM, O'Rourke MF, Safar ME: Improvement in blood pressure, arterial stiffness and wave reflections with a very-low-dose perindopril/indapamide combination in hypertensive patient: a comparison with atenolol. Hypertension 2001, 38:922-926.

22. Joy D, Thava VR, Scott BB: Diagnosis of fatty liver disease: is biopsy necessary? Eur J Gastroenterol Hepatol 2003, 15:539-543.

23. Zhou G, Myers R, Li Y: Role of AMP-activated protein kinase in mechanism of metformin action. J Clin Invest 2001, 108:1167-1174.

24. Montagnani M, Quon MJ: Insulin action in vascular endothelium: potential mechanisms linking insulin resistance with hypertension. Diabetes Obes Metab 2000, 2:285-292.

25. Meaney E, Vela A, Samaniego V, Meaney A, Asbún J, Zempoalteca JC, Elisa ZN Emma MN, Guzman M, Hicks J, Ceballos G: Metformin, arterial function, intima-media thickness and nitroxidation in metabolic syndrome: the mefisto study. Clin Exp Pharmacol Physiol 2008, 35(8):895-903.

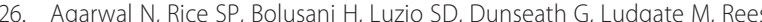
DA: Metformin reduces arterial stiffness and improves endothelial function in young women with polycystic ovary syndrome: a randomized, placebo-controlled, crossover trial. $J$ Clin Endocrinol Metab 2010, 95(2):722-730

27. Kiyici S, Ersoy C, Kaderli A, Fazlioglu M, Budak F, Duran C, Gul OO, Sigirli D, Baran I, Tuncel E, Erturk E, Imamoglu S: Effect of rosiglitazone, metformin and medical nutrition treatment on arterial stiffness, serum MMP-9 and MCP-1 levels in drug naive type 2 diabetic patients. Diabetes Res Clin Pract 2009, 86(1):44-50.

28. Mather KJ, Verma S, Anderson TJ: Improved endothelial function with metformin in type 2 diabetes mellitus. J Am Coll Cardiol 2001, 37:1344-1350

29. Huang Y, Fu JF, Shi HB, Liu LR: Metformin prevents non-alcoholic fatty liver disease in rats: role of phospholipase A2/lysophosphatidylcholine 
lipoapoptosis pathway in hepatocytes]. Zhonghua Er Ke Za Zhi 2011, 49(2):139-145.

30. Joel E: Lavine and The TONIC Randomized Controlled Trial: Effect of Vitamin E or Metformin for Treatment of Nonalcoholic Fatty Liver Disease in Children and Adolescents. JAMA 2011, 305(16):1659-1668.

31. Krakoff J, Clark JM, Crandall JP, Wilson C, Molitch ME, Brancati FL, Edelstein SL, Knowler WC: Diabetes Prevention Program Research Group. Effects of metformin and weight loss on serum alanine aminotransferase activity in the diabetes prevention program. Obesity (Silver Spring) 2010, 18(9):1762-1767.

32. Uygun A, Kadayifci A, lsik AT, et al: Metformin in the treatment of patients with non-alcoholic steatohepatitis. Aliment Pharmacol Ther 2004, 19:537-544.

33. Stefan N, Vozarova B, Funahashi T, Matsuzawa Y, Weyer C, Lindsay RS, Youngren JF, Havel PJ, Pratley RE, Bogardus C, Tataranni PA: Plasma adiponectin concentration is associated with skeletal muscle insulin receptor tyrosine phosphorylation, and low plasma concentration precedes a decrease in whole-body insulin sensitivity in humans. Diabetes 2002, 51:1884-1888.

34. Yokota T, Oritani K, Takahashi I, Ishikawa J, Matsuyama A, Ouchi N, Kihara S, Funahashi T, Tenner AJ, Tomiyama Y, Matsuzawa Y: Adiponectin, a new member of the family of soluble defense collagens, negatively regulates the growth of myelomonocytic progenitors and the functions of macrophages. Blood 2000, 96:1723-1732.

35. Kim SG, Kim HY, Seo JA, Lee KW, Oh HJ, Kim NH, Choi CM, Baik SH, Choi DS: Relationship between serum adiponectin concentration, pulse wave velocity and nonalcoholic fatty liver disease. Europ J Endocrinol 2005, 152:225-231.

doi:10.1186/1475-2840-11-61

Cite this article as: Shargorodsky et al:: Relation between augmentation index and adiponectin during one-year metformin treatment for nonalcoholic steatohepatosis: effects beyond glucose lowering? Cardiovascular Diabetology 2012 11:61.

\section{Submit your next manuscript to BioMed Central and take full advantage of:}

- Convenient online submission

- Thorough peer review

- No space constraints or color figure charges

- Immediate publication on acceptance

- Inclusion in PubMed, CAS, Scopus and Google Scholar

- Research which is freely available for redistribution 